\title{
The Man Behind the Beard: Perception of Men's Trustworthiness as a Function of Facial Hair
}

\author{
Arman Bakmazian \\ Department of Psychology, Neuroscience, and Behaviour, McMaster University, Hamilton, Canada \\ Email: arman.bakmazian@gmail.com
}

Received 19 January 2014; revised 15 February 2014; accepted 11 March 2014

Copyright (C) 2014 by author and Scientific Research Publishing Inc. This work is licensed under the Creative Commons Attribution International License (CC BY). http://creativecommons.org/licenses/by/4.0/

c) (i) Open Access

\begin{abstract}
There are several exogenous factors-such as the presence of facial hair-that can bias a male's perceived trustworthiness. Research addressing the influence facial hair that has on perceived trustworthiness is scarce; however, research suggests that facial hair promotes the perception of untrustworthiness. In the present study, participants were presented with experimental questions and two facial photographs (depicting a bearded or non-bearded face) and asked to choose the stimulus that they perceived to be more trustworthy. The results of the present study were inconsistent with previous findings (Ebling, 1987; Muscarella \& Cunningham, 1996; Neave \& Shields, 2008; Stirrat \& Perrett, 2010; Terry \& Krantz, 1993; Wogalter \& Hosie, 1991). More specifically, individuals were significantly more likely to choose bearded faces over non-bearded faces as trustworthy. Moreover, attributions of a photo's attractiveness were controlled by pre-rating it and randomly matching it with another photo with the same attractiveness rating.
\end{abstract}

\section{Keywords}

Trustworthiness; Beards; Trust; Facial Hair; Perception; Male

\section{Introduction}

Whether it warms a face or catches idle crumbs, facial hair serves many purposes for men in contemporary society. In addition to the individual's considerations of the practicality of bearing facial hair, several studies have been conducted by evolutionary psychologists to clarify the psychosocial consequences of facial hair (Ebling, 1987; Muscarella \& Cunningham, 1996). Studies have suggested that facial hair influences the initial impression of a man. In other words, facial hair influences the perception of a man's physical characteristics such as age, 
sexual maturation, and attractiveness (Ebling, 1987; Muscarella \& Cunningham, 1996; Neave \& Shields, 2008; Stirrat \& Perrett, 2010; Terry \& Krantz, 1993; Wogalter \& Hosie, 1991). The scope of the present study was to investigate whether or not the presence of facial hair can affect the initial impression of a man's trustworthiness.

One domain of research investigates the perception of a man's intelligence based on the presence of facial hair (Terry \& Krantz, 1993). With the use of rating paradigms, previous findings depict that facial hair reduces the perceived intelligence of a male (Terry \& Krantz, 1993). Terry and Krantz (1993) argue that these findings are indicative of a trade-off between social forcefulness and cognitive ability; such that individuals with beards are believed to be more forceful when pursuing sexual endeavours, which make them appear more cognitively inept (Terry \& Krantz, 1993).

Facial hair also influences perceived attractiveness. Individuals with facial hair are viewed as less attractive by the opposite sex (Muscarella \& Cunningham, 1996; Wogalter \& Hosie, 1990; Neave \& Shields, 2008). In particular, the amount of facial hair that the individual possesses can influence their perceived attractiveness (Neave \& Shields, 2008). Neave and Shields (2008) found that men with less facial hair are rated as most attractive by women, and are preferred for both short and long term relationships. They argue that females merely prefer males who can grow a beard because it indicates physical maturity, whereas they dislike full beards because they are indicative of high levels of aggression and dominance. The claim that facial hair is an indicator of aggression has been heavily supported. Men with facial hair are perceived as more aggressive than men without facial hair (Muscarella \& Cunningham, 1996; Neave \& Shields, 2008). Since the growth of facial hair is dependent on testosterone levels (Ebling, 1987), and testosterone levels are correlated to aggression (Archer, 1995; Book, Starzyk \& Quinsey, 2001), facial hair is thought to be an evolutionarily stable cue for aggression.

An aggressive appearance decreases perceived trustworthiness. Facial width is an indicator of aggression and trustworthiness (Stirrat \& Perret, 2010). Stirrat and Perret (2010) had participants play a series of economic games for real money. Each participant versed several opponents. However, unbeknownst to the participant, the opponents were edited pictures of the participant with various alterations depicting either a greater or lesser facial width. Individuals who played the trust games were more likely to trust men with narrower faces than men with greater facial width (Stirrat \& Perret, 2010). Since the presence of a beard gives off the illusion of a wider jaw line, bearded men are more likely to be perceived as less trustworthy (Stirrate \& Perret, 2010).

Given that facial hair is associated with perceived aggression, which in turn is negatively associated with trustworthiness, the present study hypothesizes that individuals perceive men with facial hair as less trustworthy than clean-shaven men. This hypothesis was tested by presenting several pairs of bearded and non-bearded male facial stimuli to participants. The participants then attempted to quickly answer indirect questions relating to "who would you trust more?" scenarios by selecting which face (bearded or non-bearded) they preferred. The present study is the first to directly assess the influence of facial hair on initial judgments of trustworthiness. However, since both men and women were tested, there were additional variables to consider. The effect of attraction was accounted for in the present study by pre-rating each male photograph for attractiveness and only presenting it side by side with other pictures of the same attractiveness rating. Also, the effect of any culturally ubiquitous negative stereotypes concerning male facial hair that could have impacted our participants' responses were isolated by using only Caucasian males with no culturally specific identifiers.

\section{Materials and Methods}

\subsection{Participants}

21 University students (5 males and 16 females) enrolled in the General Laboratory 3LL3 course at McMaster University. Participants received a course credit for their participation and provided written consent.

\subsection{Stimulus Material}

Headshot photographs of 30 Caucasian males between the ages of 18 and 30 photographed against a blank background were used as the stimuli in the experiment. The 30 faces were obtained from a pool of photographs in an online face database (Minear \& Park, 2004). The models of the photographs signed consent forms allowing their pictures to be used in further research. The faces were pre-rated for attractiveness and organized into categories in accordance with their calculated attractiveness value. The models in the photographs had a neutral expression and were clean shaven. Pictures of faces with tattoos or piercings were not used. Using Adobe Photo- 
shop CS5 software, 15 randomly selected photographs were digitally modified with added facial hair (beards and moustaches) and all photographs were converted to greyscale. The modified photographs had a realistic and natural appearance. For an example please refer to Appendix A. In total 30 unique photographs; 15 male faces with no facial hair and 15 male faces with digitally manipulated facial hair were used. Participants recorded their answers on a sheet of paper numbered from 1 to 45 with the option of choosing either the left or right side.

\subsection{Procedure}

In this study, the experimental questions were paired with facial stimuli to measure participants' perception of trustworthiness. The independent variable was the presence of facial hair on the photographs (i.e., beard or no beard). The participants' preferred face, in response to the presented questions, was our dependent variable. A timed power-point presentation was used to present the face stimuli. Each participant was provided with a single sheet of paper numbered 1 to 45 (representing the number of trials) with "L or R" after each number. The "L or R" allowed participants to record their answer during the experiment by circling which side their preferred face was on (i.e., "L" for the left side, or "R" for the right side). The sheet also required participants to fill in their age, gender, and sexual orientation (i.e. heterosexual or homosexual).

Participants were shown two different faces in three different combinations (beard vs. beard, beard vs. no beard, and no beard vs. no beard) for each of the 15 questions, in random order. The two faces, depending on the trial condition, were randomly matched to another face pre-rated for the same level of attractiveness. In each trial, participants were shown a question for five seconds. Five of the questions were worded to assess participants' perception of the men's trustworthiness, for example: Both of these men graduated from Harvard. Whom would you hire? Another five questions were worded to identify the participants' distrust of the target men, for example: Who is most likely to cheat on his girlfriend? The final five questions of the questionnaire were control questions that assessed traits and characteristics unrelated to trust or attractiveness, for example: Who is more likely to be a lead singer in a rock band? This made the experimental hypothesis less obvious to the subjects and also controlled for right/left brain preference biases. For a complete list of the questions included in our questionnaire please refer to Appendix B. After the prompting question had been on screen for five seconds, two facial stimuli were presented side by side for two seconds. By presenting the facial stimuli for only two seconds, exogenous factors beyond making an initial impression for each face was controlled. Then, participants were presented with another blank screen for five seconds. In this brief time period, participants were able to choose the face they preferred, out of the two that were presented, and record their response on their respective answer sheet.

Following the experiment, participants completed a short questionnaire designed to measure their explicit attitudes and perceptions regarding men with facial hair. Participants self-rated their degree of agreeableness for each explicit statement with the use of a 5-point Likert scale. The questionnaire included six statements that involved the extent to which bearded men are perceived as more attractive, dominant, aggressive, trustworthy, and having higher socio-economic status. Participants indicated their degree of agreeableness of each statement by circling one of five options on the 5-point Likert scale: 1 (strongly disagree), 2 (disagree), 3 (neutral), 4 (agree) and 5 (strongly agree).

\section{Results}

In the experiment, the majority of the participants preferred bearded faces to non-bearded faces for most of the experimental questions (Figure 1). The data was analyzed using a chi-square statistical test. Participants were significantly more likely to choose bearded faces over their clean-shaven counter parts when asked to assess a male's perceived trustworthiness, $X^{2}(1, N=22)=0.588, p<0.005$.

When taking into account the sexual preference of the participants, a similar pattern appeared. The data illustrates that participants, regardless of sexual preference, were more likely to choose bearded facial stimuli to non-bearded faces as their response for the experimental questions. With the use of chi-square statistical test, this analysis was proven to be significant as well, $X^{2}(1, N=22)=0.588, p>0.005$.

Moreover, the implicit data from the experiment was compared to the explicit data from the post-experimental survey. During the experiment, most participants chose bearded faces (instead of non-bearded faces) as their answer for the presented experimental questions. This behaviour correlated with the responses on the explicit post-experimental survey (Figure 2). A Pearson product-moment correlation coefficient statistical test was used 


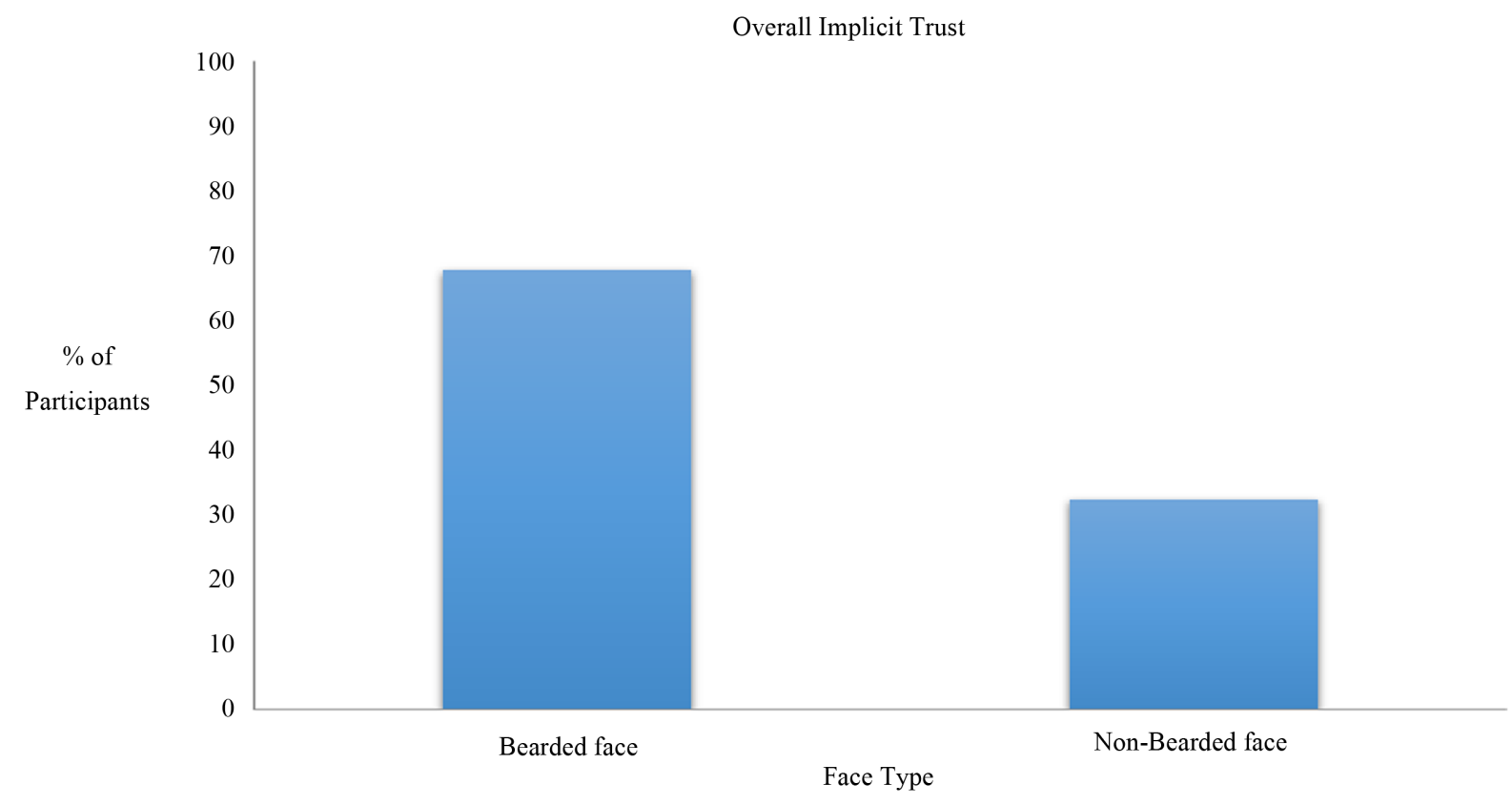

Figure 1. This table shows the difference in participants' responses between bearded faces and non-bearded faces for all experimental questions assessing trustworthiness. A higher percentage of participants chose bearded faces, than non-bearded faces, as appearing to be more trustworthy.

Relationship Between Implicit and Explicit Trust

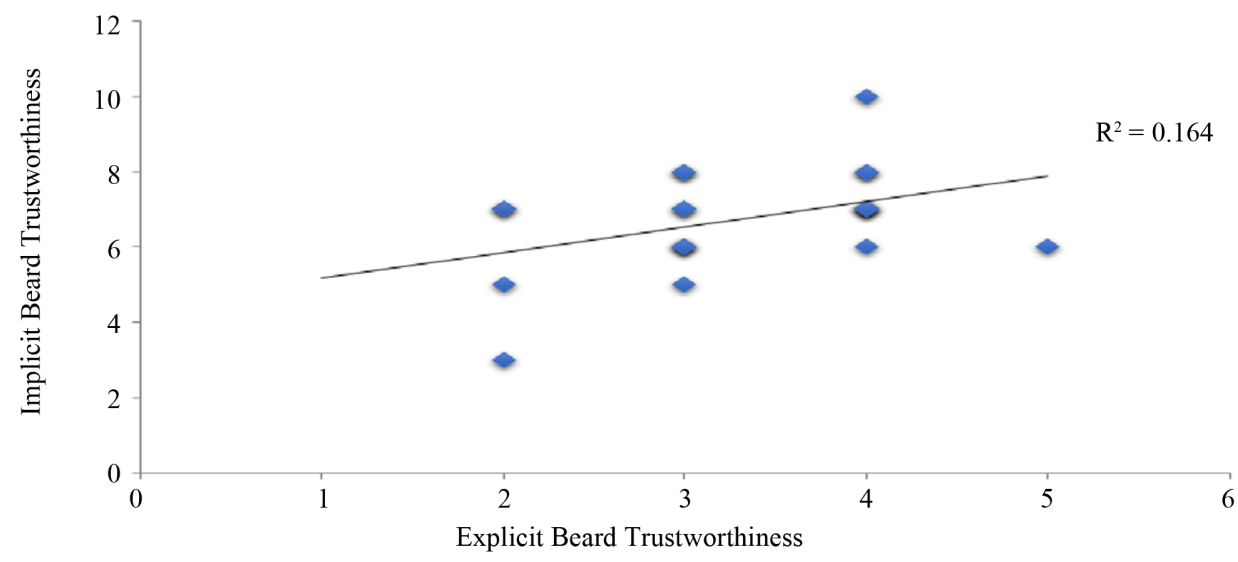

Figure 2. This table shows the correlation between participants' implicit choice of facial stimuli during the experiment and their explicit beliefs on the post-experiment survey. The $\mathrm{X}$-axis represents the level of agreeableness from the Likert scale (i.e., 1 meaning they strongly disagree, and 5 meaning they strongly agree). Also, it depicts a positive correlation (however not significant), illustrating that as participants' degree of agreeableness with the explicit statement increases, so does the frequency of bearded faces chosen during the experiment.

to illustrate the positive correlation between explicit and implicit beliefs towards bearded men, but, was not statistically significant, $r=0.405, p=0.06$. The correlation depicted that as a participant's level of agreeableness toward the statement, "I would trust a man with facial hair rather than a man without facial hair" increased, so did the participant's preference towards the pictures of bearded men.

\section{Discussion}

Previous studies suggested that the presence of facial hair decreased a male's perceived trustworthiness. How- 
ever, the present study's findings indicate that participants were significantly more likely to choose bearded faces to non-bearded faces when answering the experimental questions concerning a male's perceived trustworthiness. When sexual preference of the participants was taken into account, a similar result was found. This suggests that regardless of sexual preference, people find bearded men to be more trustworthy than non-bearded men. Also, there is a positive correlation between the implicit and explicit views of a bearded man's trustworthiness. During the experiment, participants perceived bearded men to be more trustworthy than non-bearded men. After the experiment, the participants filled out a survey that directly asked their perceptions on bearded men in relation to trustworthiness. Participants responded how much they agreed with this statement by indicating it on a 5-point Likert scale. A positive, however slightly statistically insignificant, correlation between the participants' implicit and explicit views was found regarding the perceived trustworthiness of bearded. The correlation suggests that the more a participant agrees with the trustworthy statement on the post-experimental survey, the more likely it was that said participant trusted men with beards during the experiment. Overall, participants seemed to prefer bearded faces to non-bearded faces in situations involving trust, indicating that the presence of facial hair positively influences an individual's initial impression of a man's trustworthiness.

Ultimately, the findings of the present study are inconsistent with previous research (Stirrat \& Perret, 2010). However, the present study's findings dictate that this was not necessarily the case. When participants were presented with circumstances requiring a judgment of who is more trustworthy, they were significantly more likely to choose bearded over non-bearded individuals. Essentially, the participants of this study perceived bearded males to be more trustworthy than their clean-shaven counterparts. Since confounding variables (i.e., attraction, exogenous factors like piercings and tattoos) were controlled for, it was determined that the presence of facial hair influenced the participant's perception of a male's trustworthiness.

\subsection{Limitations}

Aside from the small sample size, the participants of the present study were comprised of psychology undergraduate students from McMaster university aged 19 to 22. This specific group of participants does not accurately represent the population as a whole. University students can be considered as their own sub-culture (Aygün \& Imamoĝlu, 2002; Kutner \& Brogan, 1974; Stokoe, 2000). This suggests that university students have their own views and beliefs for different stimuli (Aygün \& Imamoĝlu, 2002; Kutner \& Brogan, 1974; Stokoe, 2000). As a result, undergraduate students may have views and beliefs towards beards that do not coincide with the rest of the general population.

Another limitation of the present study is the lack of control for pre-existing notions and prior experiences with bearded men. Antecedent research suggests that prior experiences (i.e., both favourable and unfavourable) can influence future behaviours, views and beliefs (Tversky \& Kahneman, 1975). Ultimately, if a participant had a positive or negative prior experience with a bearded male, then their responses would be heavily influenced by that predisposition to beards. Essentially, these preconceived notions could skew this study's results. Since participants were not screened for having either positive or negative preconceptions of bearded men, this serves as a limitation to the present experiment. In order to accurately test whether or not the presence of facial hair is a determining factor in perceived trustworthiness, participants with either neutral (neither good nor bad) experiences with bearded individuals would be needed.

\subsection{Implications}

The findings of the present study can be applied to virtually any situation, circumstance, or scenario in which a person encounters a man long enough to form an impression. Clearly, there are numerous situations in which this occurs. However, for the sake of conciseness, this paper will only discuss two of the major implications believed to be the most significant and practical for contemporary society.

The first implication of the present study regards the retail industry. One of the most prevalent difficulties for sales associates and spokespeople is selling products or services, in a time-limited context, to people whom they have never met (Sirdeshmukh, Singh, \& Sabol, 2002). Potential customers, because of their lack of familiarity with the sales associate, are skeptical of the sales associate's intentions/“sales pitch” (Sirdeshmukh et al., 2002). However, by altering the appearance of the sales associate (i.e., growing a beard or facial hair), potential customers may perceive the sales associate as more trustworthy. As a result, potential customers may be less skeptical towards the sales associate's "sales pitch" and more inclined to purchase the product or service, thus al- 
lowing companies and retail conglomerates to increase profits and revenue.

A second implication of the present study regards the interview process for a job or career. When applying for a position at a company, it is customary for an employer to hold interviews with all suitable applicants (Kinicki \& Lockwood, 1985). Naturally, employers seek characteristics that set an applicant apart from the others (Kinicki \& Lockwood, 1985). In essence, if an employer views trustworthiness as a valuable trait, then an applicant who is perceived to be more trustworthy (i.e., beard-bearing), will have a significant advantage over other applicants. Thus, the presence of faciawl hair may increase an applicant's chances of getting hired.

As one can imagine, there are several situations in which being perceived as more trustworthy can have benefits. With these findings in hand, a male might be able to ameliorate their trustworthiness by refraining from shaving his face for a few days.

\subsection{Future Studies}

The results from the present experiment suggest that the presence of facial hair promotes the perception of trustworthiness in males. However, these results only scratch the proverbial surface of the influence beards have on the perception of a male's trustworthiness.

The present study used male facial stimuli with light to moderate beards which were converted to grayscale in order to eliminate any confounding variables (i.e., participants' preference of facial hair color and styles). But, perhaps various facial hair colors and styles may elicit different responses from individuals. In future studies, the correlation between trustworthiness and beard density, length, and color can be investigated.

Another future study could test whether the ethnicity of a bearded male can influence their perceived trustworthiness. The present study used facial photographs of Caucasian males. Instead, a future study could use photographs of males from different races and ethnicities. This form of study could potentially involve availability heuristics and social stereotypes, which may play a role in influencing the perception of bearded males from different ethnicities (Tversky \& Kahneman, 1975). Clearly, there are several ideas for subsequent experiments that can be conducted in regards to the present study's findings.

\section{Conclusion}

Of the many utilitarian functions facial hair bestows upon males, influencing their perception of trustworthiness is one of them. Prior research indicates that facial hair generally increases perceptions of many characteristics including aggression and physical maturation, while decreasing perceptions of attractiveness and intelligence. By increasing a male's perceived aggression, socio-evolutionary psychologists have suggested that bearded males would generally be perceived as less trustworthy than non-bearded males. However, contrary to past research, the presence of facial hair increased the perception of a male's inherent trustworthiness in this study.

\section{References}

Archer, J. (1995). Testosterone and Aggression. Journal of Offender Rehabilitation, 21, 3-25. http://dx.doi.org/10.1300/J076v21n03_02

Aygün, Z. K., \& Imamoĝlu, E. O. (2002). Value Domains of Turkish Adults and University Students. The Journal of Social Psychology, 142, 333-351. http://dx.doi.org/10.1080/00224540209603903

Book, A. S., Starzyk, K. B., \& Quinsey, V. L. (2001). The Relationship between Testosterone and Aggression: A Meta-Analysis. Aggression and Violent Behavior, 6, 579-599. http://dx.doi.org/10.1016/S1359-1789(00)00032-X

Ebling, F. J. (1987). The Biology of Hair. Dermatologic Clinics, 5, 467.

Kinicki, A. J., \& Lockwood, C. A. (1985). The Interview Process: An Examination of Factors Recruiters Use in Evaluating Job Applicants. Journal of Vocational Behavior, 26, 117-125. http://dx.doi.org/10.1016/0001-8791(85)90012-0

Kutner, N. G., \& Brogan, D. (1974). An Investigation of Sex-Related Slang Vocabulary and Sex-Role Orientation among Male and Female University Students. Journal of Marriage and the Family, 36, 474-484. http://dx.doi.org/10.2307/350718

Minear, M., \& Park, D. C. (2004). A Lifespan Database of Adult Facial Stimuli. Behaviour Research Methods, Instruments, \& Computers, 36, 630-633. http://dx.doi.org/10.3758/BF03206543

Muscarella, F., \& Cunningham, M. R. (1996). The Evolutionary Significance and Social Perception of Male Pattern Baldness and Facial Hair. Ethology and Sociobiology, 17, 99-117. http://dx.doi.org/10.1016/0162-3095(95)00130-1 
Neave, N., \& Shields, K. (2008). The Effects of Facial Hair Manipulation on Female Perceptions of Attractiveness, Masculinity, and Dominance in Male Faces. Personality and Individual Differences, 45, 373-377. http://dx.doi.org/10.1016/j.paid.2008.05.007

Sirdeshmukh, D., Singh, J., \& Sabol, B. (2002). Consumer Trust, Value, and Loyalty in Relational Exchanges. The Journal of Marketing, 66, 15-37. http://dx.doi.org/10.1509/jmkg.66.1.15.18449

Stirrat, M., \& Perrett, D. I. (2010). Valid Facial Cues to Cooperation and Trust Male Facial Width and Trustworthiness. Psychological Science, 21, 349-354. http://dx.doi.org/10.1177/0956797610362647

Stokoe, E. H. (2000). Constructing Topicality in University Students' Small-Group Discussion: A Conversation Analytic Approach. Language and Education, 14, 184-203. http://dx.doi.org/10.1080/09500780008666789

Terry, R. L., \& Krantz, J. H. (1993). Dimensions of Trait Attributions Associated with Eyeglasses, Men’s Facial Hair, and Women’s Hair Length. Journal of Applied Social Psychology, 23, 1757-1769. http://dx.doi.org/10.1111/j.1559-1816.1993.tb01064.x

Tversky, A., \& Kahneman, D. (1975). Judgment under Uncertainty: Heuristics and Biases (pp. 141-162). Springer Netherlands.

Wogalter, M. S., \& Hosie, J. A. (1991). Effects of Cranial and Facial Hair on Perceptions of Age and Person. The Journal of Social Psychology, 131, 589-591. http://dx.doi.org/10.1080/00224545.1991.9713892 